\title{
Miedo, asco proyectivo y política de la exclusión: el impacto de las emociones en la construcción de la ciudadanía democrática*
}

\author{
Fear, projective disgust and the politics of exclusion: the impact of emotions on the construction of democratic \\ citizenship
}

Iván Alfonso Pinedo Cantillo ${ }^{\text {a }}$

Universidad de La Sabana (Chia), Colombia

DOI: https://doi.org/10.11144/Javeriana.papo25.mapp

ivanpc@unisabana.edu.co

ORCID: https://orcid.org/0000-0001-9319-7110

Recibido: 21 Abril 2020

Aceptado: 24 Agosto 2020

Resumen:

Publicado: 30 Diciembre 2020

En las últimas décadas, los estudios sobre la estructura cognitiva de las emociones nos permiten comprender el papel que estos fenómenos centrales y omnipresentes de la experiencia humana desempeñan en diversos ámbitos de la vida: política, educación, derecho, arte, entre otros. En este contexto, autores como Martha Nussbaum y Paul Rozin posibilitan poner al descubierto un nervio sensible para la conformación de auténticas sociedades democráticas en el siglo XXI: la aparición del miedo y el asco proyectivo como emociones que quebrantan la norma pública según la cual todas las personas merecen igual respeto y dignidad. Siendo esto así, este artículo de reflexión expone la discusión que se abre en las ciencias humanas sobre cómo las emociones nos convierten en agentes de justicia o, por el contrario, nos impulsan a generar políticas de exclusión que socavan los cimientos sobre los que se erigen los derechos humanos y la democracia. Con este enfoque de una vida pública cimentada en las emociones podemos establecer algunos derroteros para vincular aspectos motivacionales con ciertas perspectivas críticas en torno a cómo somos y cómo deberíamos ser como ciudadanos.

Palabras clave: Miedo, asco, exclusión, ciudadanía, Nussbaum.

\begin{abstract}
:
In recent decades, studies on the cognitive structure of emotions allow us to understand the role that these central and omnipresent phenomena of human experience play in various areas of life: politics, education, law, art, among others. In this context, authors such as Martha Nussbaum and Paul Rozin make it possible to uncover a sensitive nerve for the shaping of authentic democratic societies in the 21 st century: the emergence of fear and projective disgust as emotions that break the public norm according to which all people deserve equal respect and dignity. This being so, this reflective article exposes the discussion that is opening up in the human sciences on how emotions make us agents of justice or, on the contrary, drive us to generate policies of exclusion that undermine the foundations on which human rights and democracy are built. With this approach to a public life grounded in emotions we can establish some paths to link motivational aspects with certain critical perspectives on how we are and how we should be as citizens.
\end{abstract}

Keywords: Fear, disgust, exclusion, citizenship, Nussbaum..

\section{Introducción}

Martha Nussbaum, una de las voces femeninas con mayor relevancia en el campo de la reflexión ética y la filosofía política actual, en uno de sus textos más recientes, la Monarquía del miedo (2019), pone al descubierto un nervio que viene afectando a las sociedades contemporáneas: las emociones y su impacto en la construcción de una ciudadanía auténticamente democrática. Es una obra cuyo título nos sumerge en una reflexión temática recurrente en el pensamiento de la filósofa estadounidense: la comprensión psicológica y filosófica de las emociones que subyacen a la unidad, o a la división social, y las posibilidades de educación de las mismas para una convivencia en donde la cooperación constructiva abra horizontes de un futuro mejor.

La monarquía del miedo es una derivación de la teoría de las emociones que Nussbaum desarrolló más ampliamente en El ocultamiento de lo humano (2006), Paisajes del pensamiento (2008), Emociones

Notas de autor

\footnotetext{
${ }^{a}$ Autor de correspondencia. Correo electrónico: ivanpc@unisabana.edu.co
} 
politicas (2014), y Anger and Forgiveness (2016). Para la filósofa de Chicago las emociones son fenómenos que configuran nuestra existencia cotidiana, prácticamente desde las primeras horas del día estamos experimentando emociones de diversa índole: alegría, tristeza, sorpresa, ira, entre otras, no obstante, este factor tan decisivo en nuestro comportamiento no se ha relacionado suficientemente con la deliberación pública de los ciudadanos. Para nuestra autora las emociones nos pueden convertir en verdaderos agentes de justicia o, por el contrario, nos pueden arrastrar hacia conductas de exclusión, asco y subordinación de grupos que quebrantan la norma pública según la cual todas las personas merecen igual respeto y dignidad.

De acuerdo con lo anterior, en este artículo se brindan algunas ideas sobre cómo las sociedades contemporáneas están llamadas a gestionar y contener dos emociones que pueden resultar peligrosas e inquietantes para la evolución de la democracia: el miedo y su hijo, el asco proyectivo, en cuanto que son expresiones hostiles que obstaculizan el interés por los demás, defraudan la esperanza de la paz y socavan las aspiraciones a vivir en una sociedad que proteja una pluralidad de derechos para todos los ciudadanos. Para alcanzar este objetivo, se contextualizará inicialmente la teoría cognitivo-evaluativa de las emociones de Martha Nussbaum y posteriormente se enriquecerá está reflexión con algunos aportes provenientes de la psicología contemporánea, en donde se brinda un análisis evolucionista del asco. Con este enfoque de una vida pública cimentada en las emociones obtendremos algunos insumos para vincular aspectos motivacionales con las legítimas aspiraciones a la justicia, a la vez que podemos equiparnos con ciertas perspectivas críticas sobre cómo somos y cómo deberíamos ser como ciudadanos.

\section{La teoría de las emociones de Nussbaum}

En contraposición a la vieja idea de las emociones como reacciones ciegas, o impulsos descontrolados y automáticos que no podemos dominar, Nussbaum, inspirada en Aristóteles y en el estoicismo antiguo, asume una visión cognitivo-evaluativa de las emociones, es decir, entiende estos fenómenos humanos como un tipo especial de juicios: de valor o evaluaciones, que permiten ver el mundo desde el punto de vista de nuestro esquema de objetivos y proyectos; las cosas a las que asignamos valor en el marco de una concepción de lo que para nosotros significa el florecimiento de una vida humana (Nussbaum, 2008).

Hay que anotar en este punto que una teoría cognitiva de la emoción, de las cuales hay versiones tanto filosóficas como psicológicas, es aquella que incluye constitutivamente algún aspecto del pensamiento, usualmente una evaluación, juicio o creencia de cierto tipo, que es central para el concepto de emoción. Las teorías cognitivas presuponen que las emociones se basan en juicios sobre situaciones, personas o estados de cosas, y estos juicios pueden ser correctos o incorrectos, superficiales, erróneos o ilusorios. Para la mayoría de las emociones, si no en todas, la emoción que aflorará en una persona depende del modo como esta vea el objeto que ha aprehendido o crea que ha aprehendido (Lyons, 1993; Greenspan, 2004).

De acuerdo con lo anterior, si para los antiguos estoicos las emociones son juicios de valor errados porque conceden gran importancia a personas y acontecimientos externos e inestables que no están bajo el control de la virtud ni la voluntad racional de las personas, y que de fondo no tienen poder para hacernos vivir feliz o desgraciadamente, Nussbaum plantea un giro significativo frente a esta postura, al sustentar que las emociones son precisamente juicios de valor que conceden enorme importancia a los bienes vulnerables que están por fuera de nuestro control, y este reconocimiento de nuestra común fragilidad y necesidad es la base que posibilita el respeto mutuo y la reciprocidad, así como también lazos y apegos reales con nuestros seres queridos, con los miembros de nuestra comunidad e incluso con la humanidad en general (Nussbaum, 2008). La visión estoica, por su parte, prescinde de demasiadas cosas y nos deja sin el amor a la familia, a los amigos, a los demás ciudadanos, o al país, sin nada que haga que la vida valga realmente la pena (Knuuttila, 2004).

Mientras los antiguos estoicos se mantenían firmes en su ideal de que los únicos recursos que realmente necesitamos vienen de nuestro interior y de nuestras virtudes, en el neoestoicismo de Nussbaum lo propio de la 
dimensión cognitiva de ciertas emociones que son relevantes para la vida pública es la motivación que causan para interesarnos por las cosas que acontecen a los demás, al igual que el impulso interior que proporcionan para arriesgarnos en aras de la justicia social y del bien común. Esto significa que los objetos intencionales a los que se dirigen las emociones están dotados de una relevancia especial en la vida del agente, y este aspecto es fundamental para la vida moral en el sentido que permite que las personas asuman que su vida marcada por la falta de autosuficiencia, expuesta al poder que tiene el azar para destruirla, necesita completarse mediante los vínculos con los otros (Pinedo, 2019)

Así, pues, las emociones están ligadas a ciertas interpretaciones o evaluaciones que hacemos de la realidad, y basados en esos contenidos mentales que tenemos frente a los acontecimientos, experimentamos ira, tristeza, alegría y demás estados emocionales. Esta perspectiva filosófica, por tanto, establece nuevas miradas de lo cognitivo en donde los actos de valoración, las creencias y la consideración de aspectos referidos a la dignidad humana y a su vulnerabilidad son tenidos en cuenta como elementos que configuran la relación entre las emociones, el conocimiento moral y la deliberación pública de los ciudadanos.

En el trasfondo de esta teoría, Nussbaum nos hace caer en cuenta que no todas las emociones resultan constructivas para la vida en sociedad, algunas son particularmente dañinas dado el potencial que tienen para motivar prejuicios contra personas o grupos, o para impulsar lo que la filósofa denomina la "política de la exclusión". El miedo es precisamente una de estas emociones que, junto con el asco y la ira, conducen a marginar o subordinar a ciertas personas que son rotuladas en nuestro contexto como indeseables o "peligrosas" para la armonía social: migrantes, personas de determinada raza, ciertos miembros de la comunidad LGBTI, enfermos, habitantes de la calle, grupos religiosos, discapacitados, entre otros. Los seres humanos somos, pues, muy proclives a cultivar los errores en los que el miedo y la preocupación autodefensiva hacen que caiga hasta el más virtuoso si tales tendencias no se mantienen firmemente bajo control (Nussbaum, 2019). Cabe suponer, entonces, que los ciudadanos democráticos necesitarán buenas normas sociales y una adecuada educación de las emociones, para apuntalar los principios de igualdad y dignidad que fácilmente podemos olvidar en estos tiempos de especial tensión o incertidumbre, en donde el miedo tiende a ejercer su singular monarquía.

\section{Bajo el poder hegemónico del miedo}

El miedo es la emoción de un monarca absoluto a quien no le importa nada ni nadie más. El miedo naturalmente hace que evitemos situaciones que pueden poner en riesgo nuestra vida. En nuestra prehistoria evolutiva el miedo hacía que nos alejáramos de animales peligrosos, depredadores o de situaciones en las que podíamos salir gravemente lesionados. Este es un miedo racional y, podríamos decir, positivo para nuestra supervivencia (Darwin, 1984). Escapar del peligro es algo que todos los animales tienen que hacer para sobrevivir. La conducta particular que se genera al evaluar una situación como dañina depende de cada especie (correr, volar, nadar). Hasta aquí todo se puede observar con cierta normalidad. Pero en el ser humano el miedo asume ciertas características que hacen que sea una emoción distinta a lo que acontece en otras especies.

Lo primero que hay que decir es que el miedo implica la creencia o el pensamiento de una amenaza inminente a nuestro bienestar. En la Retórica, Aristóteles ya anotaba esta condición, para que exista miedo se debe caracterizar el suceso como algo muy importante para la supervivencia o el bienestar; y, segundo, que la gente tuviera la sensación de que la situación está descontrolada y que no le va a ser nada fácil protegerse de ese hecho negativo por sí sola (Nussbaum, 2019). El asunto es que nuestras evaluaciones del riesgo suelen ser imprecisas porque, en lugar de calcular fríamente costes y beneficios, y de informarnos adecuadamente sobre los acontecimientos, nos dejamos llevar por una serie de pensamientos que no nos proporcionan una buena guía para nuestro comportamiento social (Roberts, 2013). 
Uno de estos efectos es lo que Nussbaum denomina la conducta "cascada": las personas responden al comportamiento de otros individuos, sumándose rápidamente a su forma de actuar. A veces, se les unen por la reputación que un individuo tiene en una comunidad, ya sea un político, un líder religioso, o cualquier otra persona que consideremos de "buena reputación" y fiable. Este seguimiento fiel y obediente muchas veces ocasiona que el miedo empiece a ejercer su monarquía destructora. ¿Cómo funciona la exclusión?, ¿qué emociones la impulsan y la configuran?, ¿qué papel desempeña el miedo en la creación de tales jerarquías?, ¿por qué personas que han vivido durante años en paz (pueden ser judíos, hindúes y musulmanes, por ejemplo), de un momento a otro se volvían mutuamente hostiles y empezaban a definir su identidad de un modo distinto, en términos de su etnicidad religiosa? Son preguntas de fondo que hay que resolver desde el análisis de nuestro repertorio emocional. Para Nussbaum hay diversos factores que operan en las emociones, uno de ellos tiene que ver con el enorme papel que desempeñan ciertos líderes respetados de cada comunidad, cuyas reputaciones propician seguidores incondicionales más acostumbrados a seguir ideas ajenas que a pensar críticamente. En este contexto, la retórica del miedo empieza a reinar asociada a creencias distorsionadas, a pensamientos en donde se empieza a ver al otro como un peligro real o potencial que hay que extirpar o alejar (Nussbaum, 2019; Pinedo, 2021).

El líder con buena reputación extiende su poder influenciador primero a sus colaboradores más cercanos, quienes reproducen las emociones que este desea efectivamente generar, pues parte de la fidelidad al líder es compartir sus emociones; luego de boca en boca, de familia en familia, de persona a persona, se produce un contagio emocional en donde subyacen ideas de desconfianza frente a ciertas personas o grupos que pueden resultar amenazantes para la armonía de la comunidad (Scheler, 2005).

La retórica del miedo es el principal vehículo para despertar estados emocionales, donde quizá muchos \#si no hubieran oído el discurso de tal líder político, de tal pastor, o de tal maestro\# no tendrían ningún motivo para ver con desconfianza a gente que, a lo mejor, llevaban mucho tiempo tratando con tranquilidad. Como sucedió en la antigua Yugoslavia, donde personas que vivían juntas en una misma casa, unas en el piso de arriba y otras en el piso de abajo, y no sabían siquiera, ni se habían preguntado nunca si su vecino era serbio, croata o bosnio, de pronto, impulsadas por la retórica del miedo de algunos dirigentes políticos, no solo descubrieron esas identidades originarias, sino que además lo hicieron con todos los agravios que sufrieron en los siglos XV, XVI y XVII, generando una violencia con secuelas todavía hoy perceptibles.

Raza, lengua, costumbre y territorio suelen considerarse como elementos indispensables para constituir una nación; pero si se discute cada elemento de forma aislada, comienzan las dudas frente al otro. Entonces, lo que parecía fundamental para la unión empieza a verse más bien como distinto y ajeno, y si esas diferencias no se manejan apropiadamente por la presencia del miedo y la desconfianza, poco a poco se transformarán en las futuras fuentes de conflicto al interior de la nación (Kymlicka, 1996). No hay que olvidar que el miedo permanece agazapado en el trasfondo de ideas que estructuran las culturas dominantes, que tienden a ver lo diferente como un signo claro de formas de vida primitivas, atrasadas y sospechosas que, quizá, no deben ser tenidas en cuenta en el nuevo orden mundial de progreso, tecnología e innovación: ¿para qué fijarse en los que no evolucionaron ni material ni culturalmente? ¿No es mejor mirar hacia el futuro y dejar atrás esos rezagos de formas de vida ya superadas? Estos son los síntomas del imperialismo cultural, entendido como la universalización de la cultura de un grupo dominante que poco a poco va siendo naturalizada y elevada a la categoría de norma general. El resto de las culturas que no adquieren el estatus de hegemónicas son señaladas como lo otro, lo incivilizado, atrasado e inferior que no merece mayor atención en el contexto internacional (Kymlicka, 1996; Pinedo, 2013).

El miedo igualmente se aprovecha del papel destacado que tiene la introducción o circulación de nueva información sobre el peligro que presuntamente representan los otros grupos que piensan o actúan de manera diferente (musulmanes, judíos, afroamericanos, homosexuales, etc.). Nuestras democracias del siglo XXI llevan cultivando desde hace muchos años esta monarquía del miedo. Pero actualmente existe una novedad que hace que las situaciones sean más volátiles si cabe, porque las redes sociales e internet han 
hecho que sea más fácil la circulación de noticias falsas y la información de fenómenos cascada: "Las redes sociales propician hoy en día la expresión de opiniones breves y contundentes, más que la elaboración de argumentos complejos" (Nussbaum, 2019, p. 259). Las redes se han convertido en el brazo tecnológico de la monarquía del miedo, cuando, por ejemplo, una noticia se "viraliza", generando emociones descontroladas y hasta pánico. Las redes se han convertido en el escenario virtual de insultos, improperios, amenazas y demás comportamientos agresivos, ya sea motivados por aspectos políticos (candidatos de preferencia, o corrientes políticas), tendencias religiosas, o por cualquier otro detonante que conduzca a mirar al otro con recelo, y muchas veces con odio.

El problema de fondo es que el miedo no solo se circunscribe a insultos o agresiones en la red, sino que fácilmente su monarquía impulsa a la agresión real en las calles y en otros espacios públicos que deberían ser lugares de concordia y fraternidad. Hay que anotar que el miedo es amigo del fanatismo y de la sumisión a la presión del grupo. Hay personas que aun cuando sus iguales dicen cosas que son evidentemente falsas, su ceguera de pensamiento generada por la fuerza psicológica del miedo hace que sean arrastradas a mantener y continuar con tales errores y, más aún, con acciones derivadas de ideas infundadas (Frijda, 2007).

\section{Las emociones hijas del miedo: ira y asco}

El miedo como emoción no siempre actúa en solitario, frecuentemente infecta o contagia a otras emociones, o las convierte en sus cómplices más cercanos como son la ira y el asco. La ira, impulsada por el miedo, también desarrolla creencias o evaluaciones cognitivas erróneas que conducen a la violencia y los crímenes de odio. Para Nussbaum la ira es hija del miedo. Cuando el miedo anida en nuestra vida normalmente se pierde el amor hacia el otro, y con esta pérdida normalmente nos volvemos vulnerables a la ira. La ira es una evaluación cognitiva de que el otro no ha afrentado gravemente y que su acción debe ser castigada o vengada. El miedo muchas veces es una precondición para la ira vengativa y es el veneno que la alimenta. En ciertas ocasiones el miedo hace que sintamos ira sin saber a ciencia cierta contra quién y por qué. Un caso típico que Nussbaum comenta es el de la ira por miedo a perder el estatus relativo, es decir, cuando una persona se siente más que otra. Entonces en tal estado, surge el miedo del individuo que ve en los demás solo afrentas y ofensas que pretenden "rebajarlo"; la ira se asocia así al miedo generando menosprecio a otros, y tratando de ejercer poder sobre aquel que hace peligrar el estatus hasta lograr someterlo, ya sea con humillaciones, gritos, palabras soeces o cualquier otro mecanismo que la ira encuentre como vía eficaz frente al desconocimiento del "estatus relativo" (Nussbaum, 2019; Pinedo, 2021).

La ira, hija del miedo, también se alimenta de la información falsa o errónea, de la falta de pensamiento crítico y del fanatismo (Nussbaum, 2016). Un caso paradigmático lo constituye la Alemania Nazi con la propaganda antisemita. El tabloide Der Stürmer semanalmente destilaba información que hacía ver a los judíos como amenazantes a nivel social, político y económico; el editor se valía de caricaturas, tiras cómicas, ilustraciones grotescas e historias truculentas que poco a poco iban alimentando la psicología del miedo frente a gente considerada depravada o de costumbres malsanas. De ahí a la ira y los crímenes de odio solo hubo un paso, obviamente todo esto impulsado por la vehemente macroretórica del miedo generada por la jerarquía nazi. En esta línea de pensamiento, el miedo y la ira relacionada con el temor destacan especialmente en los crímenes más recientes de odio contra los musulmanes, en donde un conglomerado de ideas, no bien fundamentadas, han sido fácilmente desviadas hacia un lodazal de culpabilización y violencia vengativa, tal como se ha visto después del 11 de septiembre. Erróneamente, la palabra musulmán ha sido asociada con terrorismo, religión de extremismos, "yihadistas" que quieren destruir a Occidente, etc. Todo esto sin siquiera conocer los elementos básicos de la fe del Islam, ni los principios de vida emanados del Corán.

El otro hijo del miedo es el asco. Sabemos que el asco desde un punto de vista biológico evolutivo cumple una tarea de protegernos contra sustancias y objetos que pueden afectar nuestra salud. Pero el análisis 
contemporáneo que Nussbaum trae se orienta hacia el asco hacia personas y grupos. Para diferentes autores el asco hace parte de las emociones básicas y primitivas, ya que se trata de una reacción que surge rápidamente frente a objetos que valoramos como dañinos o contaminantes (Haidt, 2008; Rozin, 1999). Los animales también sienten asco por ciertos objetos o alimentos que consideran nocivos, o al menos no son de su agrado, y generan conductas de alejamiento. Pero en el ser humano el asco puede adquirir connotaciones diferentes como producto de su mayor complejización cognitiva. En nuestra especie el asco puede aparecer como producto de una variedad bastante amplia de creencias que hacen que no solo sea una emoción básica, sino que en ocasiones se puede transformar en una emoción compleja en donde subyacen una serie de valoraciones que están presentes en diversas relaciones humanas que únicamente son posibles desde nuestra mayor complejidad cognitiva. El asco puede estar presentes en nuestros juicios morales, en nuestras actitudes hacia temas relacionados con la sexualidad y en las creencias que vamos desarrollando sobre personas que pertenecen a otras culturas, etnias o grupos sociales (Rozin y Fallon, 1987).

Un cuerpo en descomposición, las heces o ciertos olores nos despiertan automáticamente la emoción del asco. Esta reacción básica que tiene posiblemente la función biológica de advertirnos ante ciertos riesgos de ingerir, consumir alimentos o sustancias venenosas, puede expresarse a través de ciertas imágenes o significados que hemos atribuidos a determinadas cosas. En algunos contextos encontramos que el asco no solo es una reacción natural, sino que además contiene un importante componente cognitivo vinculado a ideas de contaminación, impureza y contagio.

Los investigadores sobre el asco han hecho diferentes pruebas que demuestran cómo la emoción tiene una fuerza en nuestras reacciones viscerales y que no son fácilmente modificables en algunos casos. Por ejemplo, en el experimento en donde se le da a alguien un cepillo que se suele usar para limpiar los inodoros completamente nuevo y limpio para que lo pase por su cara y lo meta en la boca, el rechazo y las arcadas son la respuesta ante semejante solicitud (Rozin, 1999). En este caso no valen las explicaciones que el cepillo es completamente nuevo. En esta situación se ve cómo una imagen, o el conocimiento que tiene la persona de cómo o para qué se usan determinados cepillos, domina sobre las razones que se le presentan para explicarle que el objeto está completamente limpio. La reacción de asco es una manifestación fisiológica similar cuando el sujeto ve, o huele un cuerpo en descomposición, y cuando se imagina alguna suciedad en un objeto cualquiera. La imagen, o las representaciones que el sujeto construya o posea sobre determinados objetos son suficientes para generar una reacción fisiológica de rechazo.

Rozin (1999), reprodujo con diferentes objetos esta experiencia cognitiva de impureza y contaminación que puede acompañar el asco. La sopa servida en un orinal totalmente limpio resultaba mucho menos deseable que la sopa servida en un tazón; y la sopa removida con un matamoscas completamente nuevo generaba en distintas personas la idea de que ese objeto contaminante podía transferir de alguna manera sus propiedades repugnantes al alimento.

Incluso estos objetos, o las significaciones que se tengan de ellos, pueden acompañarse de muy variadas razones o explicaciones. Posiblemente el sujeto, incluso, puede reconocer que su reacción es absurda, o que es consciente de que el objeto es completamente aséptico, pero que, sin embargo, no es capaz de ponérselo en la cara o en su boca. Por supuesto, en este caso, o en otros parecidos, las razones o justificaciones pueden venir posteriormente para completar las reacciones emocionales. El sujeto puede decir, "es que nunca se sabe si en esas fábricas se producen los objetos con toda la limpieza necesaria", o "yo usualmente no me meto nada a la boca", o "ese producto es hecho en un país que hace cosas de baja calidad", etc. Independientemente de este caso, el ejemplo ilustra claramente la manifestación de las emociones básicas y las complejas. En estas últimas las representaciones de diferente naturaleza pueden generar u ocasionar una reacción emocional fuera del control del sujeto. Por supuesto, son muy variados los casos donde estas relaciones entre ideas, representaciones, o algún tipo de información, y las emociones o reacciones fisiológicas pueden presentarse. Muchas veces las ideas, o representaciones, pueden ser contradictorias, o no ser necesariamente explícitas, y 
en algunos casos pueden estar tan enraizadas en la sensibilidad que se hacen complemente rígidas y con pocas posibilidades de modificación (Haidt, 2008; Rozin, 1999).

Teniendo en cuenta este trasfondo, el punto filosófico-político que resulta relevante en este contexto es que en la vida social lo asqueroso se proyecta a menudo hacia grupos que consideramos tienen algo "contaminante" para nuestra alma o psique. Esto es lo que se llama asco proyectivo, muchas veces dirigido hacia subgrupos raciales, identificados por el color de piel u otros rasgos superficiales (Nussbaum, 2006). El temor a ser contagiados por otras personas que consideramos sucias físicamente, o "sucias" en sus ideas, sus prácticas sexuales no convencionales, su cultura o lugar de origen, genera asco proyectivo. De acuerdo con Nussbaum, en ocasiones se asocian estos grupos con rasgos de animalidad que los hacen simbólicamente polutos, por tanto, lo mejor es alejarlos de nuestro entorno. Surge así una dinámica social de miedo y segregación (la política de la exclusión): hay que permanecer lejos de los que nos pueden contaminar, que no se acerquen, que no nos toquen, que no participen de nuestras reuniones, que se escondan donde no los tengamos que ver. En otras circunstancias, el asco impulsa la discriminación por razón de discapacidad, pobreza e incluso edad. Es otra forma como el miedo ejerce su monarquía de división y desigualdad (Nussbaum, 2019).

El asco de castas en India (los intocables), el racismo estadounidense que generó en su momento conductas extremas como prohibir que los afroamericanos se bañaran en las piscinas de blancos, o el antisemitismo, son solo ejemplos de contextos que muestran a otros seres humanos con algunas características negativas que son reprobables: seres hipercorporales, hiperanimales, malolientes o con una sexualidad patológica. El miedo se mezcla en todas estas ideas generando mayores estigmas, sesgos y amenazas. En su máximo nivel conduce a los crímenes y al odio que ha causado desde persecuciones hasta guerras de exterminio (Pinedo y Yáñez, 2017a).

Más allá de sumergirnos en cualquier discusión sobre las tradiciones culturales de segregación que han existido en la humanidad, lo que interesa resaltar en este momento es cómo en el ser humano las emociones pueden alternarse en niveles de complejidad cognitiva. El asco en estado puro, como emoción básica, puede ser una emoción apropiada en donde se realiza una valoración elemental de cosas del mundo exterior que nos pueden causar daño. Pero las creencias que albergamos sobre ciertas personas o grupos pueden hacer que esta emoción corresponda a niveles superiores de cognición en donde los juicios valorativos están mediados por la cultura, el contexto social y la educación, en cuanto elementos moduladores de lo emocional. Los animales son incapaces, en general, de formarse estas complejas creencias que juegan un papel tan considerable en muchas emociones humanas (Pinedo y Yáñez, 2017b).

Como derivación de este asco proyectivo, surge también el asco moralizado, es decir, se asocian estos mismos grupos "contaminantes" físicamente, con un tipo de contaminación moral. Se alberga entonces implícitamente la idea de que no son solamente personas sucias en su corporalidad, sino que moralmente son también individuos depredadores sexuales potenciales, violadores, ladrones al acecho, mentirosos y poseedores de una serie de conductas monstruosas o reprobables desde el punto de vista moral. Gente, por tanto, que se puede tratar sin consideración y sin reconocer sus respectivos derechos humanos. El color de piel, el origen cultural, el lugar de migración, la religión y demás características que vamos encontrando en el "otro diferente", se convierten entonces en la marca de algo malo, pervertido o malsano que esconden desde un punto de vista moral (Nussbaum, 2019). Hay, pues, personas que sienten asco por un determinado grupo social y también sostienen argumentos sobre la proclividad a la delincuencia de esas personas, generando barreras invisibles de "gente mugrienta y contaminante" moralmente, y gente pura, socialdemócrata, con altos valores y virtudes.

Durante siglos los filósofos asociaron el concepto de emoción a significados morales. Aristóteles, los estoicos, Hume y los sentimentalistas británicos se referían a las emociones en términos de aquellas reacciones que expresaban un rechazo o condena a cierto tipo de conductas que generaban desaprobación (Seoane, 2004). La indignación, la culpa, la vergüenza u otras emociones se presentaban asociadas a conductas que socialmente recibían una particular valoración, o estaban estrechamente asociadas a una norma moral. Aristóteles es para muchos estudiosos el filósofo que inició el trabajo sistemático sobre la relación entre 
las emociones y la vida buena, sus reflexiones en la Ética Nicomaquea y en laRetórica dan cuenta de cómo las emociones están estrechamente vinculadas a las conductas virtuosas que ayudan a edificar la vida en sociedad, y también cómo el descontrol de las emociones genera vicio y acciones que perjudican a los demás (Kristjansson, 2018).

En el caso del asco moralizado que estamos analizando, esta emoción hace que la integración de estos grupos marginales en la vida social sea cada vez más difícil, quedando muchas veces desamparados frente a los brotes de crueldad, intolerancia y segregación que estallan por todas partes. La presencia de estos grupos "moralmente cuestionables", lejos de generar curiosidad o interés por conocer su verdadera humanidad, genera toda una atmósfera de odio y rechazo que con el tiempo se vuelve la conducta "normal" de los grupos dominantes sobre los grupos subordinados, aquellos que resultan asquerosos física y moralmente.

En todo esto juega un papel decisivo la educación de los ciudadanos y las estructuras culturales que vamos construyendo en esta época de globalización tecnológica y económica, más no de globalización de la solidaridad. La cultura, entendida como una forma abreviada de entender las creencias compartidas, las significaciones y los valores mostrados por los miembros individuales de una sociedad, o de una subcultura dentro de esa sociedad, influye poderosamente en el etiquetaje de las emociones, en las evaluaciones que conforman las emociones y en la determinación de los comportamientos que tienden a despertar estados emocionales específicos (Solomon, 2007). La cultura también afecta la manera en que se experimentan las emociones al dotarlas de valoraciones positivas o negativas. Como se aprecia en el caso del asco proyectivo, la cultura, y dentro de esta ciertas prácticas sociales particulares, afectan la vida emocional de un modo más sustantivo definiendo los comportamientos que pueden ser vistos como objetos apropiados de desprecio, vergüenza y miedo (Nussbaum, 2014).

El miedo y su emoción aliada el asco proyectivo, finalmente impactan en la aspiración a una ciudadanía mundial que busca resolver de manera cooperativa los principales problemas de la humanidad. Vivimos unos frente a otros cruzando fronteras geográficas y de lenguaje, venimos de naciones heterogéneas, pero el miedo espera cualquier prejuicio, cualquier sospecha que surja frente a las tradiciones ajenas, para resquebrajar la confianza en el otro, y desbaratar el ideal democrático de ser hombres y mujeres con una capacidad empática para acoger respetuosamente las diferencias (Nussbaum, 2010). Así, hoy seguimos reafirmando que elegimos la democracia y el autogobierno, y suponemos que apostamos por la libertad, los derechos humanos y la tolerancia, pero, si no atendemos al miedo que está acechando en lo oculto y muy cercano, la vida misma de la democracia puede estar en peligro.

\section{Conclusiones}

Nussbaum con su amplia erudición, pero también con su diáfana manera de escribir salpicada de ejemplos ilustrativos, nos sumerge en una reflexión poco explorada por la filosofía contemporánea: la relación entre las emociones, la vida moral y la deliberación pública de los ciudadanos. La monarquía del miedo (2019),El ocultamiento de lo humano (2006), o Anger and Forgiveness (2016), son textos paradigmáticos que nos hacen pensar en el ambiente cotidiano de nuestras grandes metrópolis, caracterizado por la falta de solidaridad, la indiferencia frente al sufrimiento ajeno y los prejuicios generados por interpretaciones erróneas de los acontecimientos que influyen en nuestro repertorio emocional. Si algo podemos percibir en las sociedades del siglo XXI es un miedo recurrente frente al que es de otra raza, cultura, religión u orientación sexual, por solo poner algunas ideas generales. Pero lo relevante de esta fotografía que Nussbaum hace del mundo actual es el trasfondo que nos invita a pensar en cómo la democracia se fractura cuando los ciudadanos, sometidos a esta dictadura del miedo, desconocemos la dignidad que hay en el otro, y con esto rompemos los lazos sociales que permiten el avance hacia la consecución de ideales de libertad, justicia e igualdad. En otras palabras, nos alejamos de construir un mundo más humano. 
No obstante, la filósofa de Chicago nos propone un horizonte de esperanza mediante la educación de las emociones a través de la imaginación literaria, la música, las artes y un espíritu de deliberación y de crítica racional encarnado en la filosofía (Modzelewski, 2017). Muchos ciudadanos carecen de sentido común. Tienden con demasiada frecuencia a pensar las cosas en términos narcisistas: me interesa solo lo que sea bueno para mí y para mi familia. Como las personas no coinciden ni entran en contacto traspasando los límites de las grandes divisiones sociales, les cuesta mucho pensar en un sentido de propósito común que vaya más allá de su propio grupo económico o social. Así, dice la filósofa, somos más proclives al miedo que a la compasión y la solidaridad. Pero la escuela y universidad pueden romper estos modelos de sociedad egoísta invitando a leer obras que ayuden a comprender qué se siente ser de otra raza, religión y cultura, y ser excluido socialmente por el miedo que esto genera en mentes llenas de prejuicios: ¿Realmente esa persona es tan mala como yo me imagino que es?, ¿̇ufrirá, tendrá familia?, ¿cuáles son sus sueños?, ¿ por qué vive así? La imaginación literaria puede hacer este efecto de superar las barreras invisibles que genera la desconfianza en el otro. También la danza, el teatro y otras expresiones artísticas que permiten interactuar con el que creemos que es diferente, y que nos causa miedo por sus costumbres pueden derrumbar la hegemonía de esta emoción que divide y hace tambalear los cimientos mismos de la democracia (Nussbaum, 2019).

Las narraciones que tengan en cuenta las emociones y la sensibilidad habrán de ocupar un lugar fundamental en la educación de los ciudadanos, pues la capacidad imaginativa e inventiva de la literatura resulta relevante para identificarse con el otro, comprender de manera simpática sus razones, deseos y esperanzas, y de alguna manera hacer el ejercicio de ponernos en su lugar (De Tienda, 2015). La literatura, al poner en funcionamiento el maravilloso mecanismo de la imaginación, permite la representación de una vivencia distinta a la mía, y mediante recursivos ejercicios empáticos hace posible incorporar la experiencia del otro en mi propia vida, y de esta manera genera elementos vinculantes (Modzelewski, 2017). La literatura es, pues, una "escuela de humanidad" que posibilita una percepción de las situaciones y de las personas más detallada y compleja; es una vía privilegiada para cultivar las cualidades que nos hacen más humanos porque despierta un genuino interés por los otros (Pena, 2016).

Cuando nos reunimos para bailar o cantar, para representar una obra de teatros juntos, en donde cada uno aporta su talento y destrezas para la puesta en escena, compartiendo el contacto físico y las metas comunes en torno a la obra, estamos acortando distancias y combatiendo el miedo mediante una reconfortante sensación de trabajo y gozo en común. La educación de las emociones a través de la imaginación literaria y las artes es un camino posible para sensibilizar a los nuevos ciudadanos de nuestras metrópolis, pero la discusión no se agota en estos recursos. Prácticamente en los últimos diez años se ha abierto un amplio campo de estudio interdisciplinar para entender cuáles deben ser los métodos más eficaces para educar a los niños y jóvenes en estos fenómenos que son tan definitorios de nuestra esencia humana. Aquí estamos avivando la reflexión, vinculando los estudios sobre el miedo y el asco a las investigaciones que ya existen sobre el factor emocional y su impacto en los cimientos de la democracia.

El miedo parece que no ha perdido su hegemonía, las nuevas xenofobias dan cuenta de esta realidad, no obstante, confío en que estas reflexiones sirvan de inspiración para continuar las discusiones sobre la relación entre emoción, cognición y vida moral. Igualmente, los planteamientos aquí formulados generan ciertos derroteros para futuros debates sobre la importancia de la educación de las emociones para consolidar sociedades auténticamente democráticas que no renuncien al ideal de hacer del planeta una casa para todos, en donde podamos vivir con dignidad, bajo un mismo cielo, pero con diferentes horizontes.

\section{Referencias}

Darwin, C. (1984). La expresión de las emociones en los animales y el hombre. Alianza. 
De Tienda, L. (2015). El papel de las emociones y la literatura en la deliberación pública: la figura del equilibrio perceptivo de Martha C. Nussbaum. ARBOR Ciencia, Pensamiento y Cultura, 191(773), a241. https://www.d oi.org/10.3989/arbor.2015.773n3011

Frijda, N. (2007). The Laws of Emotions. Lawrence Erbaum Associates.

Greenspan, P. (2004). Practical Reasoning and Emotion. En A. Mele, y P. Rawling (Eds.), The Oxford handbook of rationality (pp. 206-211). Oxford University Press.

Haidt, J. (2008). Disgust. En M. Lewis (Ed.), Handbook of Emotions (pp. 757-776, 3a ed.). Guilford Press.

Knuuttila, S. (2004). Emotions in Ancient and Medieval Philosophy. Clarendon Press.

Kristjansson, K. (2018). Virtuous Emotions. Oxford University Press.

Kymlicka, W. (1996). Ciudadanía multicultural. Una teoría liberal de los derechos de las minorías. Paidós.

Lyons, W. (1993). Emoción. Anthropos.

Modzelewski, H. (2017). Emociones, educación y democracia. Una proyección de la teoría de las emociones de Martha Nussbaum. UNAM.

Nussbaum, M. (2006). El ocultamiento de lo humano. Repugnancia, verguenza y ley. (G. Zadunaisky, Trad.) Katz. (Obra original publicada en 2004).

Nussbaum, M. (2008). Paisajes del pensamiento. La inteligencia de las emociones. (A. Maira, Trad.) Paidós. (Obra original publicada en 2001).

Nussbaum, M. (2010). Sin fines de lucro. Por qué la democracia necesita de las humanidades. (M. Rodil, Trad.) Katz. (Obra original publicada en 2010).

Nussbaum, M. (2014). Emocionespoliticas. ¿Por qué el amor es importante para la justicia? (A. Santos Mosquera, Trad.) Paidós. (Obra original publicada en 2013).

Nussbaum, M. (2016). Anger and Forgiveness. Resentment, Generosity, Justice. Oxford University Press.

Nussbaum, M. (2019). La monarquia del miedo. Una mirada filosófica a la crisis politica actual. (A. Santos Mosquera, Trad.) Paidós. (Obra original publicada en 2018).

Pena, C. (2016). El cultivo de las emociones y la imaginación narrativa en Martha Nussbaum. Una propuesta para la promoción del desarrollo humano en las sociedades interdependientes del siglo XXI. Revista Deusto de Derechos Humanos, 1, 175-195. http://doi.org/10.18543/djhr-1-2016pp175-195

Pinedo, I. (2013). Filosofía multicultural y educación para la convivencia ciudadana. Praxis \& Saber, 4(7), 179-199. h ttps://doi.org/10.19053/22160159.2055

Pinedo, I. (2019). Vida buena, vulnerabilidad y emociones: la relevancia ética de los acontecimientos incontrolados desde la perspectiva de Martha Nussbaum. Universitas Philosophica, 36(73), 187-214. https://doi.org/10.1114 4/Javeriana.uph36-73.vbve

Pinedo, I. (2021). Martha Nussbaum. La monarquía del miedo. Una mirada filosófica a la crisis política actual. Ideas y Valores, 70 (176), 202-207. http://doi.org/10.15446/ideasyvalores.v70n176.71163

Pinedo, I., y Yáñez, J. (2017a). Las emociones y la vida moral: una lectura desde la teoría cognitivo-evaluadora de Martha Nussbaum. Veritas, 36, 47-72. https://doi.org/10.4067/S0718-92732017000100003

Pinedo, I., y Yáñez, J. (2017b). La dimensión cognitiva de las emociones en la vida moral: los aportes de Martha Nussbaum al estado actual de la discusión. Cuestiones de Filosofia, 3(20), 105-127. https://doi.org/10.19053/0 1235095.v3.n20.2017.5919.

Roberts, R. (2013). Emotions in the Moral Life. Cambridge University Press.

Rozin, P. (1999). Disgust: The Body and Soul Emotion. En T. Dalgleish, y M. Power (Eds.), Handbook of Cognition and Emotion (pp. 429-445). John Wiley \& Sons.

Rozin, P., y Fallon, A. (1987). A Perspective on Disgust. Psychological Review, 94, $23-41$.

Scheler, M. (2005). Esencia y formas de la simpatía. Sígueme.

Seoane, J. (2004). Del sentido moral a la moral sentimental: el origen sentimental de la identidad y ciudadania democrática. Siglo Veintiuno Editores. 
Iván Alfonso Pinedo Cantillo. Miedo, asco proyectivo y política de la exclusión: el impacto...

Solomon, R. (2007). Ética emocional: una teoría de los sentimientos. Paidós.

\section{Notas}

* Artículo de investigación científica.

Licencia Creative Commons CC BY 4.0

Cómo citar este artículo: Pinedo, I. (2020). Miedo, asco proyectivo y política de la exclusión: el impacto de las emociones en la construcción de la ciudadanía democrática. Papel Político, 25. https://doi.org/10.1114 4/Javeriana.papo25.mapp 